\title{
Prevalence and Associated Factors of
}

Psychological Distress Among Nurses in public Hospitals, Southwest, Ethiopia: A Cross-Sectional Study Design

\author{
Alemayehu Sayih Belay ( $\sim$ Alex.sayihalem2018@gmail.com ) \\ Mizan Tepi University \\ Melak Menberu Guangul \\ Bahir Dar University \\ Wondwossen Niguse Asmare \\ Mizan-Tepi University
}

\section{Research}

Keywords: Factors, Nurses, Prevalence, Psychological distress, Ethiopia

Posted Date: July 27th, 2020

DOI: https://doi.org/10.21203/rs.3.rs-48073/v1

License: (c) (i) This work is licensed under a Creative Commons Attribution 4.0 International License.

Read Full License 


\section{Abstract}

Background: Psychological distress is broadly defined as a state of emotional suffering characterized by symptoms of depression and anxiety combined by other somatic symptoms like; insomnia, headaches, and lack of energy that is likely to vary across different areas. Therefore, this study aimed at assessing the prevalence of psychological distress and its' associated factors among nurses in public hospitals, Southwest Ethiopia, 2017/18.

Method: An institutional-based cross-sectional study was conducted in public hospitals, Southwest Ethiopia from February $1^{\text {st }}, 2018$ to April $1^{\text {st }}, 2018$. The total number of nurses who fulfill the inclusion criteria were enrolled. Data was collected using the predesigned tool like Self-Reporting Questionnaire version 20 (SRQ 20). Data were entered using EPI INFO version 7 and was exported to statistical packages for social science (SPSS) version 21.0 for analysis. Bivariate and multivariate logistic regression was employed and odds ratio with $95 \%$ confidence interval was used to assess the degree of association between variables. Variables with a P-value of less than 0.05 were considered as statistically significant.

Result: A total of 282 eligible nurses were enrolled in the study with mean age of 28.71 [SD \pm 7.047 ]. The prevalence of psychological distress among nurses was 78(27.7\%). Predictor variables like; job title $[\mathrm{AOR}=10.13,95 \% \mathrm{Cl}(1.85,55.41)]$, work experience [AOR= 4.98, 95\% $\mathrm{Cl}(1.59,15.568)]$, interaction with staffs $[\mathrm{AOR}=.305,95 \% \mathrm{Cl}(.117, .796)]$, fatigue $[\mathrm{AOR}=2.54,95 \% \mathrm{Cl}(1.072,6.02)]$, social support [AOR= $.189,95 \% \mathrm{Cl}(.075, .474)]$, perfectionism [AOR= 5.697, $95 \% \mathrm{Cl}(1.449,22.39)]$ and insomnia [AOR= 3.82, $95 \% \mathrm{Cl}(1.52,9.579)]$ were found to be strong predictor variables for psychological distress.

Conclusion: This study revealed that a considerable proportion of nurses had psychological distress. Therefore, strong social support, upgraded working status, and good interaction with staff should be encouraged among nurses working in the health setting to cope up with different stressors.

\section{Introduction}

Psychological distress (PD) is broadly defined as a state of emotional suffering characterized by symptoms of depression (e.g., loss of interest; unhappiness; desperateness) and anxiety (e.g., restlessness; feeling tense) [1]. It is also characterized by other somatic symptoms like; insomnia, headaches, and lack of energy that are likely to vary across different areas [2, 3].

According to the Diagnostic and Statistical Manual of Mental Disorders, Fifth Edition (DSM-5), psychological distress defines as "undifferentiated group of symptoms ranging from anxiety and depression symptoms to functional impairment, personality traits (confusing, troubling), and behavioral problems [4].

Psychological distress is also considered as a transient (not long-lasting) phenomenon that is associated with specific stressors $[5,6]$ and characterized by disturbances in sleep, fluctuations with the eating 
pattern, headache, constipation, diarrhea, chronic pain, provoked to anger frequently, excessive tiredness, forgetfulness and memory problems, and no longer finding pleasure in sex. It typically diminishes/ vanishes when either the individual adapts to the stressor, or the stressor is removed [7].

Psychological distress among health care workers is common, especially among nurses [6]. Because they were providing continual care for those chronically ill patients, where the nature of the job by itself facing nurses to an increasing workload and risk of infection to different communicable diseases [8]. Therefore, they are susceptible to psychological distress and other complex emotional reactions. Furthermore, the mental health problems of nurses would impair their cognitive functioning, attention to health procedures, and clinical decision-making capacity. In general, their psychological distress will have an impact on the quality of health services [9] and patient satisfaction [8, 10]. High expectations, lack of time and skills, and poor social support [11] can also cause occupational stress and psychological distress which can lead to post-traumatic stress disorder [12].

Psychological distress also increases the risk of heart disease [13] and decrease immunity, thus increases the risk to different illness [14]. It also affects the quality of life and work, including overall well-being, social relationships, and family life. Moreover, this can result in higher turnover, work absences, early withdrawal, and lower quality of health services $[13,14]$.

The prevalence of psychological distress is ranged between $5 \%$ and $27 \%$ in the general population [1519] while the study conducted in Nigeria revealed that it raises up to $44.1 \%$ among nurses [20]. Therefore, the high prevalence of psychological distress among nurses due to poor interaction among staff and workload also contributes to high turnover [21] and decrement of job satisfaction [22] which become a global issue [23].

Since nurses contribute a major role in the provision of direct care for the patients in every health institution twenty-four hours a day, and seven days a week [24], assessing for the prevalence of psychological distress and its associated factors in public hospitals of southwest Ethiopia will be helpful for policymakers to provide the timely intervention.

Even though few studies on the prevalence of psychological distress in Ethiopia have been previously done, those studies are conducted among students [11, 25, 26], prisoners [27], patients [28] and family caregivers [29]. Therefore, this study aimed to assess the prevalence and associated factors of psychological distress among nurses in public hospitals, southwest Ethiopia.

\section{Methods}

\section{Study design and period}

An institutional-based cross-sectional study design was carried out at public Hospitals from February 1st, 2018 to April 1st, 2018.

\section{Study setting}


The study was conducted in public hospitals located in zones of Southwest Ethiopia. These are MizanTepi University Teaching Hospital, Gebretsadik Shawo General Hospital, and Tepi General Hospitals, which are located in Benchi-Maji Zone, Kefa Zone, and Sheka Zone respectively. Mizan-Tepi University Teaching Hospital has located $561 \mathrm{~km}$ from the capital city Addis Ababa and $844 \mathrm{~km}$ from the regional city Hawasa. Gebretsadik Shawo Hospital is found in Bonga town and located $464 \mathrm{~km}$ from Addis Abeba and $739 \mathrm{~km}$ from regional city Hawasa. Tepi General Hospital is found in Tepi and located $611 \mathrm{~km}$ from Addis Abeba. All of these hospitals have immunization departments, delivery ward, inpatients wards, outpatient departments, antenatal and post-natal clinic. Currently, Mizan-Tepi University Teaching Hospital is expected to provide service for more than 829,000 populations. While Gebretsadik Shawo General Hospital and Tepi General Hospitals are expected to provide care for more than 500,000 populations. Mizan-Tepi University Teaching Hospital, Tepi General Hospital, and Gebretsadik Shawo General Hospital have 106, 94, and 82 nurses respectively whose work experience is one or more years.

\section{Study Participants}

To be included, participants had to fulfil the following criteria: (1) have a minimum of year work experience in the same workplace or a similar health setting, (2) age 18 years and older and (3) being nurse and working in public hospitals. But those who were critically ill and unable to give response during data collection time were excluded.

\section{Data collection tools and procedure}

The data was collected using a self- administered questionnaire by six trained health professionals' and three supervisors. The questionnaire was pretested among $5 \%$ of the sample size in health centers which were out of the study settings. The coherence and skipping pattern of the questionnaire were corrected after the pretest.

For psychological distress (anxiety, depression, and somatization), the Self-Reporting Questionnaire version 20 (SRQ 20) was used, which was developed by World Health Organization (WHO) for low and middle-income countries including Ethiopia [30,31]. It has a "YES" or "No" questions and can be used as a self-administered or interviewer-administered questionnaire [32]. SRQ 20 is a 20 item questionnaire commonly used to screen anxiety, depression, and somatization symptoms [33]. We used the cut-off point 8 based on the finding from the validation study of SRQ-20 which gave the highest sensitivity and specificity [32].

To assess social support, Oslo Social Support Scale was used. Oslo Social Support Scale Score is ranged from 3-14 with a score of 3-8 = poor social support; $9-11=$ intermediate social support; and 12-14= strong social support [34].

For perfectionism, a self-assessment perfectionism screening test was used. It has "yes" if it's generally true and "no" if it's generally not true. Five or more yes answers suggest a significant problem with perfectionism. This is a screening test [35]. 
Sleep disturbance was measured by the Athens insomnia scale (AIS). The AIS is an 8-item self-reported questionnaire that indicates insomnia within the past month and scores each ranging from 0 to 3 ( 0 score equals better and 3 is worst). The total score greater than or equals to 6 indicates insomnia [36, 37].

\section{Data analysis}

The data was entered using EPI INFO version 7 and was exported to statistical packages for social science (SPSS) version 21.0 for data cleaning and analysis. Bivariate logistic regression was done to see the degree of association between independent variables (socio-demographic, organizational related factors, psycho-social related factors), and dependent variable (psychological distress) were assessed. Variables with a P-value of $<0.05$ were recruited for multivariate analysis to control the effects of confounding. Finally, the results considering a confidence level of $95 \%$ and P-value of $<0.05$ were taken as strong predictors for psychological distress. The results were presented in the form of tables, figures, and summary statistics.

\section{Result}

\section{Socio-Demographic Characteristics of the Respondents}

A total of 282 eligible nurses were included in the study with a $100 \%$ response rate. Among the respondents, most of 125 (44.3\%) was in the age range of 25-29 years with a mean age of 28.71 [SD \pm 7.047], more than half of participants 144 (51.1\%) were female, 91 (32.3\%) were Amhara by ethnicity, 120 (42.6\%) were currently single, 158 (59.6\%) had diploma educational status, 157 (58.6\%) were orthodox religion members followed by protestant $34.3 \%$. Concerning the respondents' working years of experience in the current health institution, most $138(48.9 \%)$ of them had $1-3$ years of experience [Table 1]. 
Table 1

Socio-demographic characteristics of participants in public hospitals, South West Ethiopia, 2017/18

\begin{tabular}{|lll|}
\hline Variable & Frequency & Percent (\%) \\
\hline Sex & 138 & 48.9 \\
Female & 144 & 51.1 \\
\hline Age in year & 73 & 25.9 \\
20-24 & 125 & 44.3 \\
25-29 & 35 & 12.4 \\
30-34 & 25 & 8.9 \\
35-39 & 24 & 8.5 \\
>=40 & & \\
\hline Marital status & 120 & 42.6 \\
Single & 106 & 37.6 \\
Married & 23 & 8.2 \\
Divorced & 17 & 6.0 \\
Widowed & 16 & 5.7 \\
Separate & & 58.5 \\
\hline Educational status & 168 & 59.6 \\
Diploma nurse & 114 & 40.4 \\
Bsc nurse & & \\
\hline Religion & 165 & 5.6 \\
Orthodox & 89 & \\
Protestant & 19 & \\
Muslim & 9 & \\
Catholic & & \\
\hline
\end{tabular}

* Gurage, Sidama, Wolayeta 


\begin{tabular}{|c|c|c|}
\hline Variable & Frequency & Percent (\%) \\
\hline Ethnicity & 91 & 32.3 \\
\hline Amhara & 53 & 18.8 \\
\hline Kaffa & 42 & 14.9 \\
\hline Oromo & 33 & 11.7 \\
\hline Sheka & 22 & 7.8 \\
\hline Bench & 17 & 6.0 \\
\hline Tigre & 9 & 3.2 \\
\hline Dawaro & 15 & 5.3 \\
\hline \multicolumn{3}{|l|}{ Others * } \\
\hline Job title & 232 & 82.3 \\
\hline Staff Nurse & 23 & 8.2 \\
\hline Specialist Nurse & 27 & 9.6 \\
\hline \multicolumn{3}{|l|}{ Head Nurse } \\
\hline Year Of Experience & 138 & 48.9 \\
\hline$<3$ & 66 & 23.4 \\
\hline $3-5$ & 56 & 19.9 \\
\hline $6-10$ & 13 & 4.6 \\
\hline $11-15$ & 9 & 3.2 \\
\hline \multicolumn{3}{|l|}{$>15$} \\
\hline * Gurage, Sidama, V & layeta & \\
\hline
\end{tabular}

\section{Organizational and psycho-social related variables}

Among all respondents, more than half of respondents did not get sufficient reward for their work 160 (56.7\%), the majority 221 (78.4\%) of nurses had good interaction with their co-workers, $237(88.4 \%)$ of them were practiced caring of dying patients, and more than half $150(53.2 \%)$ of the participants were planning to leave their working environment in the near future.

More than half of respondents 155 (55.0\%) had intermediate social support, whereas 65 (23\%) and 62 (22\%) of them had low and strong social support respectively. From the total participants about 107 (37.9\%) had fatigue syndrome, $244(86.5 \%)$ had a problem with perfectionism and 51(18.1\%) had a major problem with sleep [Table 2]. 
Table 2

Organizational and psycho-social related variables of participants in selected public hospitals, South West Ethiopia, 2017/18

\begin{tabular}{|c|c|c|}
\hline Variable & Frequency & Percent \\
\hline Having insufficient reward & 160 & 56.7 \\
\hline Yes & 122 & 43.3 \\
\hline \multicolumn{3}{|l|}{ No } \\
\hline Having good interaction with other staffs & 221 & 78.4 \\
\hline Yes & 61 & 21.6 \\
\hline \multicolumn{3}{|l|}{ No } \\
\hline Caring of dying patients & 248 & 87.9 \\
\hline Yes & 34 & 12.1 \\
\hline \multicolumn{3}{|l|}{ No } \\
\hline Intending to leave working environment & 150 & 53.2 \\
\hline Yes & 132 & 46.8 \\
\hline \multicolumn{3}{|l|}{ No } \\
\hline Fatigue & 175 & 62.1 \\
\hline No & 107 & 37.9 \\
\hline \multicolumn{3}{|l|}{ Yes } \\
\hline Social support & 65 & 23.0 \\
\hline Poor & 155 & 55.0 \\
\hline Intermediate & 62 & 22.0 \\
\hline \multicolumn{3}{|l|}{ Strong } \\
\hline Problem with perfectionism & 38 & 13.5 \\
\hline No & 244 & 86.5 \\
\hline \multicolumn{3}{|l|}{ Yes } \\
\hline Sleeping problem & 131 & 46.5 \\
\hline Normal sleep & 100 & 35.5 \\
\hline Minor problems with sleep & 51 & 18.1 \\
\hline Major problems with sleep & & \\
\hline
\end{tabular}


The prevalence of psychological distress among nurses was 78(27.7\%) with 95\% Cl (22\%, 33\%).

\section{Factors associated with psychological distress}

Based on bivariate analysis variables like; age, job title, year of experience, interaction with staff, fatigue, social support, perfectionism, and insomnia were the factors found to be significantly associated with psychological distress.

After adjusting for possible confounders with multivariate analysis; job title, work experience, interaction with staff, fatigue, social support, perfectionism, and insomnia were found to be strong predictor variables for psychological distress.

The odds of having psychological distress were almost 10 times more likely in those participants with the job title of a staff nurse as compared with a head nurse [AOR $=10.13,95 \% \mathrm{Cl}(1.85,55.41)]$. Participants whose working experience were 6-10 years were almost 5 times more likely to have psychological distress than those participants with experience of $1-3$ years [AOR $=4.98,95 \% \mathrm{Cl}(1.59,15.568)]$. Nurses with good interaction with other staff members were $30.5 \%$ times less likely to be psychologically distressed as compared with their counterparts $[A O R=.305,95 \% \mathrm{Cl}(.117, .796)]$. Participants with fatigue were 2.5 times more likely to have psychological distress as compared with their counterparts [AOR = $2.54,95 \% \mathrm{Cl}(1.072,6.02)]$. Those participants with intermediate social support were $18.9 \%$ times less likely to have psychological distress than those with poor social support $[\mathrm{AOR}=.189,95 \% \mathrm{Cl}(.075, .474)]$.

Besides, participants with perfectionism were almost six times more likely to develop psychological distress than their counterparts [AOR $=5.697,95 \% \mathrm{Cl}(1.449,22.39)]$. The odds of having psychological distress were almost 4 times more likely in those participants with a minor problem with sleep as compared with those participants with normal sleep [AOR $=3.82,95 \% \mathrm{Cl}(1.52,9.579)]$ [Table 3]. 
Table 3

Bivariate and multivariate analysis of predictor variables for psychological distress in selected public hospitals, South West Ethiopia, 2017/18

\begin{tabular}{|c|c|c|c|c|}
\hline \multirow[t]{3}{*}{ Variables } & \multicolumn{2}{|c|}{$\begin{array}{l}\text { Psychological } \\
\text { Distress }\end{array}$} & \multirow{3}{*}{$\begin{array}{l}\text { COR } \\
(95 \% \mathrm{Cl})\end{array}$} & \multirow{3}{*}{$\begin{array}{l}\text { AOR } \\
(95 \% \mathrm{Cl})\end{array}$} \\
\hline & No & Yes & & \\
\hline & $\mathbf{N}(\%)$ & $\mathbf{N}(\%)$ & & \\
\hline \multicolumn{5}{|l|}{ Age } \\
\hline $20-24$ & $53(72.6)$ & $20(27.4)$ & $1.00^{+}$ & $1.00^{+}$ \\
\hline $25-29$ & $96(76.8)$ & $29(23.2)$ & $.801(.413-1.551)$ & $.410(.153-1.096)$ \\
\hline $30-34$ & $30(85.7)$ & $5(14.3)$ & $.442(.150-1.297)$ & $.048(.008-1.313)$ \\
\hline $35-39$ & $9(36.0)$ & $16(64.0)$ & $4.71(1.795-12.37)^{\star}$ & $4.640(.891-24.160)$ \\
\hline$>=40$ & $16(66.7)$ & 8(33.3) & $1.325(.491-3.574)$ & $.072(.005-1.048)$ \\
\hline \multicolumn{5}{|l|}{ Job title } \\
\hline Staff Nurse & 163(70.3) & $69(29.7)$ & $\begin{array}{l}5.291(1.220- \\
22.957)^{\star}\end{array}$ & $\begin{array}{l}10.125(1.85- \\
55.41)^{*}\end{array}$ \\
\hline Specialist Nurse & 16(69.6) & $7(30.4)$ & $\begin{array}{l}5.469(1.007- \\
29.701)^{\star}\end{array}$ & $2.917(.311-27.352)$ \\
\hline Head Nurse & $25(92.6)$ & $2(7.4)$ & $1.00^{+}$ & $1.00^{+}$ \\
\hline \multicolumn{5}{|l|}{ Year of Experience } \\
\hline$<3$ & 105(76.1) & $33(23.9)$ & $1.00^{+}$ & $1.00^{+}$ \\
\hline $3-5$ & $54(81.8)$ & 12(18.2) & $.707(.338-1.479)$ & $2.148(.753-6.126)$ \\
\hline $6-10$ & $32(57.1)$ & $24(42.9)$ & $2.386(1.236-4.61)^{\star}$ & $\begin{array}{l}4.980(1.59- \\
15.568)^{*}\end{array}$ \\
\hline $11-15$ & $5(38.5)$ & $8(61.5)$ & $5.091(1.56-16.63)^{\star}$ & $6.081(.419-88.241)$ \\
\hline$>15$ & $8(88.9)$ & $1(11.1)$ & $.398(.048-3.298)$ & $4.256(.122-147.88)$ \\
\hline \multicolumn{5}{|c|}{ Good Interaction with staffs } \\
\hline Yes & 172(77.8) & $49(22.2)$ & $.314(.174-.570)^{\star}$ & $.305(.117-.796) *$ \\
\hline
\end{tabular}

*Adjusted for all significant variables at $p<0.05$,

$\mathrm{COR}=$ crude odds ratio $\mathrm{AOR}=$ adjusted odds ratio, $\mathrm{Cl}=$ confidence interval

${ }^{+}=$Reference Category 


\begin{tabular}{|c|c|c|c|c|}
\hline \multirow[t]{3}{*}{ Variables } & \multicolumn{2}{|c|}{$\begin{array}{l}\text { Psychological } \\
\text { Distress }\end{array}$} & \multirow{3}{*}{$\begin{array}{l}\text { COR } \\
(95 \% \mathrm{Cl})\end{array}$} & \multirow{3}{*}{$\begin{array}{l}\text { AOR } \\
(95 \% \mathrm{Cl})\end{array}$} \\
\hline & No & Yes & & \\
\hline & $\mathbf{N}(\%)$ & $\mathbf{N}(\%)$ & & \\
\hline No & $32(52.5)$ & $29(47.5)$ & $1.00^{+}$ & $1.00^{+}$ \\
\hline \multicolumn{5}{|l|}{ Fatigue } \\
\hline No & 135(77.1) & $40(22.9)$ & $1.00^{+}$ & $1.00^{+}$ \\
\hline Yes & $69(64.5)$ & $38(35.5)$ & $1.859(1.094-3.159) *$ & $\begin{array}{l}2.540(1.072- \\
6.02)^{*}\end{array}$ \\
\hline \multicolumn{5}{|l|}{ Social support } \\
\hline Poor & $33(50.8)$ & $32(49.2)$ & $1.00^{+}$ & $1.00^{+}$ \\
\hline Intermediate & $123(79.4)$ & $32(20.6)$ & $.268(.144-.500)^{\star}$ & $.189(.075-.474)^{*}$ \\
\hline Strong & 48(77.4) & $14(22.6)$ & $.301(.139-.649)^{\star}$ & $.919(.291-2.902)$ \\
\hline \multicolumn{5}{|l|}{ Perfectionism } \\
\hline No & $33(86.8)$ & $5(13.2)$ & $1.00^{+}$ & $1.00^{+}$ \\
\hline Yes & $171(70.1)$ & 73(29.9) & $2.818(1.058-7.505)^{\star}$ & $\begin{array}{l}5.697(1.449- \\
22.39)^{\star}\end{array}$ \\
\hline \multicolumn{5}{|l|}{ Insomnia } \\
\hline Normal sleep & 119(90.8) & $12(9.2)$ & $1.00^{+}$ & $1.00^{+}$ \\
\hline $\begin{array}{l}\text { Minor problems with } \\
\text { sleep }\end{array}$ & $67(67.0)$ & $33(33.0)$ & $\begin{array}{l}4.884(2.365- \\
10.088)^{\star}\end{array}$ & $3.82(1.52-9.579)$ * \\
\hline $\begin{array}{l}\text { Major problems with } \\
\text { sleep }\end{array}$ & 18(35.3) & $33(64.7)$ & $\begin{array}{l}18.181(7.960- \\
41.526)^{*}\end{array}$ & $\begin{array}{l}21.24(12.82- \\
92.71)^{\star}\end{array}$ \\
\hline \multicolumn{5}{|c|}{ *Adjusted for all significant variables at $p<0.05$} \\
\hline \multicolumn{5}{|c|}{$\mathrm{COR}=$ crude odds ratio $\mathrm{AOR}=$ adjusted odds ratio, $\mathrm{Cl}=$ confidence interval } \\
\hline${ }^{+}=$Reference Category & & & & \\
\hline
\end{tabular}

\section{Discussion}

The aim of this study was to identify the prevalence of psychological distress and associated factors. In addition to this, the findings of this study will have a significant role towards overcoming of the problems associated with psychological distress among nurses, like; job dissatisfaction and lack of energy which negatively affects their perception of the quality of life and health services in the workplace and the 
relationship with the patient and family [38]. Conversely, nurses with their job satisfaction increases showed reduced psychological distress [39].

In this study, the prevalence of psychological distress was $78(27.7 \%)$ with $95 \% \mathrm{Cl}(22 \%, 33 \%)$, and this study was found to be low when it is compared with a study done in Nigeria $44.1 \%$ [20]. The possible explanation for the difference in prevalence may be due to the difference in study setting, study population, tools, and methodological differences. For instance, in a study conducted in Nigeria, the tool named General Health Questionnaire (GHQ-12)was used whereas, the Self-Reporting Questionnaire version 20 (SRQ 20) was used in our study.

In contrast to the other study, this study was found to be higher compared with the studies conducted in different areas, wherein Norwegian 13\% [40], in Sri Lanka 21\% [41], in Addis Ababa, Ethiopia 11.7\% [42], and in another study conducted in Addis Ababa, Ethiopia 17.7\% [43].

This discrepancy might be for the reason that there might be a difference in a study setting, study population, tools, and methodological differences. Another possible explanation might be due to the nature of their work that nurses are more prone to experience psychological distress than the general population in the community.

Different independent predictor variables associated with psychological distress were identified in this study.

In this study, the job title was found to be significantly associated with psychological distress. The odds of having psychological distress were almost 10 times more likely in those participants with a job title of staff nurse as compared with a head nurse. This might be due to the fact that those nurses in the position of staff nurse may experience more distress and less job satisfaction because they spend more time with patients. Conversely, nurses working in managerial positions, generally have more professional experience and a higher level of education, which factors can help them to cope with different stressors and also increase job satisfaction [44].

Work experience was also found to be significantly associated with psychological distress. Participants whose working experience was 6-10 years were almost 5 times more likely to have psychological distress than those participants with experience of 1-3 years. This finding also noted in London that year of work is associated with psychological distress [45]. This might be explained by those nurses who worked for a long duration of time in the health setting are more subjected for emotional exhaustion, lack of energy, and general fatigue which in turn leads to the experience of psychological distress [46].

This study found interaction with other staff members was also another predictor variable for psychological distress. Nurses with good interaction with other staff members were $30.5 \%$ times less likely to be psychologically distressed as compared with their counterparts. This finding is in line with the study conducted in Virginia, USA [47], and in Texas [48]. This is due to the fact that nurses with good interaction among staff and family members have a chance to discuss and seek solutions for the issues 
which interfere with their stability and motivation for work. In contrast to this, poor interaction can negatively affect their physical as well as mental health [49].

In this study, fatigue among nurses was considered as a significant variable for psychological distress. Participants with fatigue were 2.5 times more likely to have psychological distress as compared with their counterparts. This is supported by a study from Iran [50] and Rhine-Main-Region, western Mid-Germany [51]. This might be for a reason that nurses with fatigue are commonly experienced with a devastating sense of drowsiness, lack of energy, and impaired cognitive and/or physical functioning, which may lead to a health problem, decrement of performance, increased risk of injury/accident, and low personal achievement, which possibly experience psychological distress [52-54].

Social support was found to be another factor associated with psychological distress in this study. Those participants with intermediate social support were $18.9 \%$ times less likely to have psychological distress than those with poor social support. This finding is also supported by the study conducted in China [55] and in Sri Lanka [41]. A plausible explanation to this could be the fact that nurses with good social support can have good mental and physical health [56-58], where this leads to the good cognitive function and performance of concentrated health care procedure which finally increases the quality of health care services [59].

Besides, this study investigated that participant with perfectionism was a predictor variable for psychological distress. Participants with perfectionism were almost six times more likely to develop psychological distress than their counterparts. This finding was supported by the study conducted in the United States Western University, USA [60]. This is due to the fact that perfectionism is a driving force of negative stress in some nurses [61]. Because perfectionist nurses who were more concerned about faults, obsessed with higher quality of work, and had more worries about their capabilities regarding the patient care are more prone to be psychologically distressed [62-64].

Insomnia was also another important predictor variable in this study. The odds of having psychological distress were almost 4 times more likely in those participants with a minor problem with sleep as compared with those participants with normal sleep. This is supported by the study conducted in Finland [65], in the USA [66], and in Samara, Ethiopia [67]. The reasonable justification could be the fact that nurses with sleep problem become disoriented for their work and further it increases the likelihood of subsequent psychological distress [68-70].

\section{Conclusion}

This study revealed that a considerable proportion of nurses had psychological distress. Job title, work experience, interaction with staff, fatigue, social support, perfectionism, and insomnia were found to be strong predictor variables for psychological distress. Therefore, strong social support, upgraded working status, and good interaction with staff should be encouraged among nurses working in the health setting to cope up with different stressors. 


\section{Limitation}

Even though this study contributes as an input for the policymakers towards the decrement of the psychological distress among nurses, it has its own limitations. First, since a cross-sectional study design was implemented, it can't establish cause-effect relationship between the predictor variables and dependent variables. Second, the tools used to assess psychological distress was not validated in Ethiopia. Finally, other health professionals were not included, which limited us not to compare nurses with other health professionals.

\section{List of abbreviations}

\begin{tabular}{|ll|}
\hline AIS & Athens Insomnia Scale \\
\hline MTUTH & Mizan Tepi University Teaching Hospital \\
\hline PD & Psychological Distress \\
SRQ- 20 & Self-Reporting Questionnaire-20 \\
\hline Declarations \\
\hline
\end{tabular}

\section{Declarations}

\section{Ethics approval and consent to participate}

The study was approved by the research standing committee of Mizan Tepi University, college of health science with a reference number $\mathrm{CHS} / 0246 / 15 / 19$. In addition to this, permission letter was taken from each hospital administration office. After explaining the objectives of the study, written consent was obtained from each study participant. Then after data was collected with strict privacy and assuring confidentiality.

\section{Consent for publication}

Not applicable

\section{Availability of data and materials}

The datasets generated during and/or analyzed during the current study are available from the corresponding author on reasonable request. Email: Alex.sayihalem2012@gmail.com

\section{Competing interests}


The authors declare that they have no competing interests

\section{Funding}

The study was funded by Mizan Tepi University.

Author's contributions

AS contributed to design the work, contributed to the data entry, participated in the statically analysis of the result, write the results, discussion, conclusion and recommendation sections, and drafted the article. MM searched the literature, and trained data collectors and also contributed to design the work, approved the version to be published, and contributed to the pretest of the tool. WN searched the literature, and trained data collectors. He also critically analyzed, reviewed and edited the results, discussion, conclusion and recommendation sections, and involved drafting the manuscript,

\section{Acknowledgements}

We are grateful to Mizan Tepi University for technical support. We are also very indebted to extend our gratitude to the respondents who offered their time to participate in this study.

\section{References}

1. Horwitz AV. Selecting outcomes for the sociology of mental health: Issues of measurement and dimensionality. Journal of health and social behavior, 2002. 43(2).

2. Kleinman A, Rethinking psychiatry. 2008: Simon and Schuster.

3. Kirmayer LJ. Cultural variations in the response to psychiatric disorders and emotional distress. Soc Sci Med. 1989;29(3):327-39.

4. Association AP, Diagnostic and statistical manual of mental disorders (DSM-5®). 2013: American Psychiatric Pub.

5. Horwitz AV. Distinguishing distress from disorder as psychological outcomes of stressful social arrangements. Health:. 2007;11(3):273-89.

6. Ridner SH. Psychological distress: concept analysis. Journal of advanced nursing. 2004;45(5):53645.

7. Kane S. Factors Linked to Psychological Distress. as it appeared on 23 Jun 2020 11:35:19 GMT]; Available from: https://psychcentral.com/lib/factors-linked-to-psychological-distress/.

8. Dollard MF, et al. Job stress in the Australian and international health and community services sector: A review of the literature. International Journal of Stress Management. 2007;14(4):417.

9. Health IDo, Division CNP, The Nursing and Midwifery Resource: Final Report of the Steering Group, Towards Workforce Planning. 2002: Department of Health and Children. 
10. Zhu Z, et al., COVID-19 in Wuhan: Immediate Psychological Impact on 5062 Health Workers. 2020.

11. Dachew BA, Bisetegn TA, Gebremariam RB. Prevalence of mental distress and associated factors among undergraduate students of University of Gondar, Northwest Ethiopia: a cross-sectional institutional based study. Plos one. 2015;10(3):e0119464.

12. Shasha J, Shi, Kong Q, Chu, Impact of COVID-19 on psychology of nurses working in the emergency and fever outpatient:A crosssectional survey. BMC 2020.

13. Parent-Thirion A, et al. Fourth European working conditions survey, European foundation for the improvement of living and working conditions. Luxembourg: Office for Official Publications of the European Communities; 2007. pp. 37-61.

14. Health, Executive S, Tackling Work-related Stress: A Managers Guide to Improving and Maintaining Employee Health and Well-being. HS (g) 218. 2001: HSE Books.

15. Benzeval M, Judge K. Income and health: the time dimension. Soc Sci Med. 2001;52(9):1371-90.

16. Chittleborough $\mathrm{CR}$, et al. Age differences in associations between psychological distress and chronic conditions. International journal of public health. 2011;56(1):71-80.

17. Gispert R, et al. Sociodemographic and health-related correlates of psychiatric distress in a general population. Soc Psychiatry Psychiatr Epidemiol. 2003;38(12):677-83.

18. Kuriyama S, et al. Factors associated with psychological distress in a community-dwelling Japanese population: the Ohsaki Cohort 2006 Study. Journal of epidemiology. 2009;19(6):294-302.

19. Phongsavan $P$, et al. Social capital, socio-economic status and psychological distress among Australian adults. Soc Sci Med. 2006;63(10):2546-61.

20. Okwaraji F, En A. Burnout and psychological distress among nurses in a Nigerian tertiary health institution. Afr Health Sci. 2014;14(1):237-45.

21. Price JL, Reflections on the determinants of voluntary turnover. International Journal of manpower, 2001.

22. Price M. Job satisfaction of registered nurses working in an acute hospital. British journal of nursing. 2002;11(4):275-80.

23. Kingma M. Nursing migration: global treasure hunt or disaster-in-the-making? Nurs Inq. 2001;8(4):205-12.

24. FDRE M. Nursing Care Practice Standards Version 2. Addis Ababa. Ethiopia: FDRE MOH (Federal Democratic republic of Ethiopia Ministry of Health); 2011.

25. Jini D, et al. Mental distress and its associated factors among students of Mizan Aman Health Science College, Ethiopia. J Med Sci. 2017;17(2):61-7.

26. Dessie Y, Ebrahim J, Awoke T. Mental distress among university students in Ethiopia: a cross sectional survey. Pan African Medical Journal, 2013. 15(1).

27. Dachew BA, et al. Psychological distress and associated factors among prisoners in North West Ethiopia: cross-sectional study. International journal of mental health systems. 2015;9(1):39. 
28. Tesfaye SH, Bune GT. Generalized psychological distress among HIV-infected patients enrolled in antiretroviral treatment in Dilla University Hospital, Gedeo zone, Ethiopia. Global health action. 2014;7(1):23882.

29. Sintayehu $M$, et al. Prevalence of mental distress and associated factors among caregivers of patients with severe mental illness in the outpatient unit of Amanuel Hospital, Addis Ababa, Ethiopia, 2013: Cross-sectional study. J Mol Psychiatry. 2015;3(1):9.

30. Tesfahunegn TB, Gebremariam EH. Mental distress and associated factors among Aksum University students, Ethiopia: a cross-sectional study. BMC Psychiatry. 2019;19(1):71.

31. Islam FMA. Psychological distress and its association with socio-demographic factors in a rural district in Bangladesh: A cross-sectional study. PloS one, 2019. 14(3).

32. Youngmann R, et al. Adapting the SRQ for Ethiopian populations: a culturally-sensitive psychiatric screening instrument. Transcultural Psychiatry. 2008;45(4):566-89.

33. Beusenberg M, Orley JH, Organization WH. A User's guide to the self reporting questionnaire (SRQ. Geneva: World Health Organization; 1994.

34. Abiola T, Udofia O, Zakari M. Psychometric properties of the 3-item oslo social support scale among clinical students of Bayero University Kano, Nigeria. Malaysian Journal of Psychiatry. 2013;22(2):32-41.

35. Shepherding S. Perfectionism Test 2018 it appeared 18-06-20]; Available from: http://www.soulshepherding.org/2012/07/perfectionism-test/.

36. Soldatos CR, Dikeos DG, Paparrigopoulos TJ. The diagnostic validity of the Athens Insomnia Scale. J Psychosom Res. 2003;55(3):263-7.

37. Soldatos CR, Dikeos DG, Paparrigopoulos TJ. Athens Insomnia Scale: validation of an instrument based on ICD-10 criteria. J Psychosom Res. 2000;48(6):555-60.

38. Bastos RA, Quintana AM, Carnevale F. Psychological Distress Experienced by Nurses who Work with Patients in Death Process: A Clinical-Qualitative Study. Temas Em Psicologia. 2018;26(2):795-805.

39. Amati $\mathrm{M}$, et al. Relationship of job satisfaction, psychological distress and stress-related biological parameters among healthy nurses: a longitudinal study. Journal of occupational health. 2010;52(1):31-8.

40. Nerdrum P, Geirdal A. Psychological distress among young Norwegian health professionals. Professions and Professionalism, 2014. 4(1).

41. Jayawardene $W$, et al. Psychological distress among nurses caring for victims of war in Sri Lanka. Disaster Med Public Health Prep. 2013;7(03):278-86.

42. Kebede D, Alem A, Rashid E. The prevalence and socio-demographic correlates of mental distress in Addis Ababa. Ethiopia Acta psychiatrica scandinavica. 1999;100:5-10.

43. Gelaye B, et al., Prevalence and correlates of mental distress among working adults in Ethiopia. Clinical practice and epidemiology in mental health: CP \& EMH, 2012. 8: p. 126. 
44. Cimete G, Gencalp NS, Keskin G. Quality of life and job satisfaction of nurses. J Nurs Care Qual. 2003;18(2):151-8.

45. Jenkins R, Elliott P. Stressors, burnout and social support: nurses in acute mental health settings. Journal of advanced nursing. 2004;48(6):622-31.

46. Duli S. Years of Work Experience, an Important Predictor of Burnout in Special Education. American Scientific Research Journal for Engineering Technology Sciences (ASRJETS). 2016;17(1):318-22.

47. Decker FH. Occupational and nonoccupational factors in job satisfaction and psychological distress among nurses. Res Nurs Health. 1997;20(5):453-64.

48. Umberson D, Karas J, Montez. Social relationships and health: A flashpoint for health policy. Journal of health social behavior. 2010;51(1_suppl):S54-66.

49. Blue A. Poor Social Skills May Be Harmful to Mental and Physical Health. Nov. 6, 2017 as it appeared on 24 Jun 2020 00:02:43 GMT]; Available from: https://uanews.arizona.edu/story/poor-social-skillsmay-be-harmful-mental-and-physical-health.

50. Azmoon $\mathrm{H}$, et al., The relationship between fatigue and job burnout dimensions in hospital nurses. Health Scope, 2018. 7(2).

51. Rose D, et al. Associations of fatigue to work-related stress, mental and physical health in an employed community sample. BMC Psychiatry. 2017;17(1):167.

52. Rogers $\mathrm{AE}$, The effects of fatigue and sleepiness on nurse performance and patient safety, in Patient safety and quality: An evidence-based handbook for nurses. 2008, Agency for Healthcare Research and Quality (US).

53. Loge $\mathrm{JH}$, Ekeberg $\varnothing$, Kaasa $\mathrm{S}$. Fatigue in the general Norwegian population: normative data and associations. J Psychosom Res. 1998;45(1):53-65.

54. Bültmann U, et al. The relationship between psychosocial work characteristics and fatigue and psychological distress. Int Arch Occup Environ Health. 2002;75(4):259-66.

55. Zhang $\mathrm{H}$, et al. Anxiety symptoms and burnout among Chinese medical staff of intensive care unit: the moderating effect of social support. BMC Psychiatry. 2020;20:1-7.

56. Harandi TF, Taghinasab MM, Nayeri TD. The correlation of social support with mental health: A metaanalysis. Electronic physician. 2017;9(9):5212.

57. Ozbay F, et al. Social support and resilience to stress: from neurobiology to clinical practice. Psychiatry (Edgmont). 2007;4(5):35.

58. Uchino BN. Understanding the links between social support and physical health: A life-span perspective with emphasis on the separability of perceived and received support. Perspectives on psychological science. 2009;4(3):236-55.

59. Huppert F, et al. The factor structure of the General Health Questionnaire (GHQ-30). Br J Psychiatry. 1989;155:178-85.

60. Kelly J, Clark H, Perfectionism among nursing students. International Journal of Nursing \& Clinical Practices, 2017. 2017. 
61. Hajloo N, et al. Survey the relationship between perfectionism and job burnout in nurses. Journal of Guilan University of Medical Sciences. 2011;20(77):23-30.

62. Flett GL, et al. Perfectionism, components of stress reactivity, and depressive symptoms. Journal of Psychopathology Behavioral Assessment. 2016;38(4):645-54.

63. Chang $Y$. The relationship between maladaptive perfectionism with burnout: Testing mediating effect of emotion-focused coping. Personality Individ Differ. 2012;53(5):635-9.

64. Chang EC. Perfectionism and dimensions of psychological well-being in a college student sample: A test of a stress-mediation model. J Soc Clin Psychol. 2006;25(9):1001-22.

65. Salo P, et al. Insomnia symptoms as a predictor of incident treatment for depression: prospective cohort study of 40,791 men and women. Sleep Med. 2012;13(3):278-84.

66. Pigeon WR, et al. Is insomnia a perpetuating factor for late-life depression in the IMPACT cohort? Sleep. 2008;31(4):481-8.

67. Tesfaye Kelemu R, Bayray A, Kahsay, Ahmed KY, Prevalence of mental distress and associated factors among Samara university students, Northeast Ethiopia. Depression research and treatment, 2020. 2020.

68. Stamatakis KA, Kaplan GA, Roberts RE. Short sleep duration across income, education, and race/ethnic groups: population prevalence and growing disparities during 34 years of follow-up. Ann Epidemiol. 2007;17(12):948-55.

69. Vgontzas A, et al. Short sleep duration and obesity: the role of emotional stress and sleep disturbances. Int J Obes. 2008;32(5):801-9.

70. Breslau N, et al. Sleep disturbance and psychiatric disorders: a longitudinal epidemiological study of young adults. Biol Psychiatry. 1996;39(6):411-8. 